\title{
PROGRAMA UM COMPUTADOR POR ALUNO EM ESCOLAS PÚBLICAS DE SANTA CATARINA: NOTAS SOBRE A SEDUÇÃO CONTEMPORÂNEA POR TUDO DIGITALIZAR
}

Fernando Cesar Sossai ${ }^{1}$

Gabriele Mendes da Silva²

Geovana Mendonça Lunardi Mendes ${ }^{3}$

\section{RESUMO}

Neste artigo analisamos algumas empreitadas do governo brasileiro voltados à difusão de tecnologias da informação e comunicação no ensino público escolar. A partir de um conjunto variado de fontes coletadas em campo, esforçamo-nos para perscrutar os sentidos das linguagens que se envolveram com a implantação e recontextualização curricular do Programa Um Computador por Aluno numa escola pública da cidade de Brusque, no sul do Brasil. De modo geral, o artigo conclui que a dispersão de tecnologias da informação e comunicação nas escolas públicas do país parece ser uma forma dos órgãos de governo agenciar linguagens supostamente habilitadas a lidar com ansiedades contemporâneas preocupadas com o tudo digitalizar.

Palavras-chave: Tecnologia da informação e comunicação. Linguagem. Currículo.

\footnotetext{
${ }^{1}$ Mestre, e-mail: fernandosossai@gmail.com

${ }^{2}$ Mestre, e-mail: gabrieletb@hotmail.com

32Doutora, e-mail: geolunardi@gmail.com
} 


\section{PRÓLOGO}

Em estudo recentemente traduzido para o português, o filósofo italiano Giorgio Agamben (2011) analisou as maneiras pelas quais o juramento, na antiguidade grega, funcionava como suporte de uma relação visceral entre política e religião. Para ele, o juramento, como "ato verbal que realizava um testemunho", era uma forma de instituir ao mesmo tempo em que interrogar a centralidade da linguagem nas sociedades antigas que 0 utilizavam.

A partir da sua "arqueologia do juramento", Agamben (2011, p. 82) concluiu que "talvez tenha chegado a hora de questionar o prestígio de que a linguagem usufruiu e usufrui em nossa cultura, enquanto instrumento de potência, eficácia e beleza incorporáveis". Entre os argumentos do autor está o fato de que o exercício humano da linguagem "não é mais belo que o canto dos pássaros, nem é mais eficaz que os sinais trocados entre si pelos insetos, nem sequer é mais poderoso que o rugido com que o leão afirma 0 seu senhorio". Assim, o imperativo que "confere à linguagem humana as suas virtudes peculiares não reside no ser que fala, enquanto disponibiliza dentro de si uma forma de vazio que o locutor toda vez deve assumir para falar". Além disso, no contemporâneo temporalidade híbrida na qual presente, passado e futuro se misturam de tal forma que não mais conseguimos identificar, sentir e separá-los em nosso cotidiano - a linguagem, se pensada de modo ensimesmado, é insuficiente para lidar com o caráter movediço das próprias referências que a edificam.

Impulsionados pelas questões abertas por Agamben (2011), neste artigo historicizamos algumas das políticas nacionais de educação relacionadas com a difusão de tecnologias da informação e comunicação no ensino básico, especialmente aquelas ligadas ao Programa Um Computador por Aluno (PROUCA): uma estratégia criada pelo governo brasileiro para promover a "inclusão digital nas escolas de ensino federal, estadual, distrital, municipal ou nas escolas sem fins lucrativos de atendimento a pessoas com deficiência" a partir da distribuição de laptops para alunos e professores (BRASIL, 2012a).

Em um segundo momento, com base num conjunto variado de fontes coletadas em campo, analisamos o processo de recontextualização deste programa em uma escola pública da cidade de Brusque estado de Santa Catarina, atentando para as linguagens que alunos e professores mobilizam e utilizam para dar sentido e significar as inovações curriculares que supostamente se desdobram e tal programa.

Tratamos, pois, de perscrutar os arranjos educativos que se revelam por meio de atos de linguagem registrados em documentos escritos provenientes de órgãos oficiais de educação, de reportagens da imprensa e dos discursos de educadores que diretamente se envolveram na implantação e recontextualização do PROUCA na escola pesquisada. Enfim, tentamos seguir pelas pistas deixadas por Agamben (2011) para refletir sobre os modos pelos quais alunos e professores se apropriam de tecnologias da informação e comunicação para significar a cultura escolar da qual cotidianamente participam. 
Ademais, destacamos que este artigo é um resultado parcial do projeto de pesquisa Aulas Conectadas? Mudanças Curriculares e Aprendizagem Colaborativa entre as escolas do PROUCA em Santa Catarina, financiado pelo CNPq, e visa socializar análises sobre a inserção de tecnologias da informação e comunicação no ensino público brasileiro, assim como receber contribuições para aprofundamento desta investigação.

\section{PROUCA: UMA BUSCA PELA DIGITALIZAÇÃO DA CULTURA ESCOLAR?}

"É muito importante que a gente [governo do Brasil] construa uma estratégia sólida para que a escola possa formar e preparar essa nova geração para o uso de tecnologias da informação" (BRASIL, 2012b). Essa foi a principal preocupação de futuro demonstrada pelo atual ministro da educação do Brasil, Aloizio Mercadante, em reportagem veiculada pela sua assessoria de imprensa em fevereiro de 2012. Em que pese a sensibilidade do ministro em relação às demandas de tecnológicas da informação e comunicação no cotidiano das escolas públicas brasileiras, nada há de novo em suas palavras. Explicamos o aludido tomando como referência alguns dos projetos governamentais que, nos últimos vinte anos, tentaram assegurar a digitalização das escolas públicas do país.

Desde 1996, dois programas do Ministério da Educação tem se destacada no âmbito da produção e distribuição de tecnologias digitais às escolas: o TV Escola e DVDescola.

Em se tratando de microcomputadores, entre os anos de 1997 e 2006, a estratégia governamental que mais se destacava era o Programa Nacional de Informática na Educação (Prolnfo). Por meio dele, no período aludido, foram adquiridos mais de 147 mil microcomputadores, distribuídos para 15 mil estabelecimentos de ensino, custando quase 240 milhões de reais aos cofres públicos. Além disso, até 2006, o censo escolar brasileiro acusava que 348 mil escolas estavam conectadas a internet, sendo que 201 mil delas possuíam laboratórios de informática, totalizando três milhões e oitocentos mil microcomputadores inseridos na dinâmica escolar do país.

Paralelo a isso, foram criados cerca de 500 Núcleos de Tecnologias Educacionais (NTE), em diferentes municípios do país, com o objetivo de promover a formação continuada de professores para o uso das tecnologias da comunicação e informação em sala de aula, especialmente os microcomputadores que estavam sendo distribuídos de modo massivo (Brasil, 2008).

Ao abrigo desse ideário foi criado pelo governo federal o Programa Um Computador por Aluno (PROUCA). Embora tenha ganhado visibilidade nacional apenas nos últimos dois anos, a criação desse programa remonta a 2007 quando foi implantado, em caráter experimental, em cinco escolas de diferentes cidades brasileiras (São Paulo, Porto Alegre, Palmas, Piraí e Brasília). 
Após três anos, o PROUCA foi oficializado por intermédio da Lei 12.249, de 14 de junho de 2010. A partir de então, o MEC, em parceria com as secretarias estaduais e municipais de educação, dedicou-se a oferecer gratuitamente laptops para alunos, professores e demais educadores de escolas públicas do país. Desses arranjos decorreu que, em 2008, quando ainda era uma experiência piloto, foram distribuídos 150 mil computadores para 380 escolas da rede pública. Em 2010, numa etapa mais avançada, foram entregues aos estudantes de 372 municípios aproximadamente 375 mil computadores (BRASIL, 2012a).

Programas como o PROUCA parecem, então, investir no entendimento de que o computador, ora como ferramenta, ora como paradigma para a edificação de novas relações com o conhecimento escolar, é um artefato capaz de promover a ligação entre o visível e o invisível, entre o local e o global, entre o micro e o macro e, principalmente entre um presente escolar saturado de passados e um futuro no qual a educação pública, além de garantir o acesso ao saber, assegurará também a inclusão digital da população brasileira. Uma espécie de futuro do presente no qual utopias educacionais parecem ser suportadas pelo estímulo ao uso pedagógico de tecnologias da informação e comunicação na escola, assim como por estratégias governamentais que delas se valem para mediar nossas ansiedades contemporâneas por tudo digitalizar.

\section{PROUCA EM SANTA CATARINA: HISTORICIDADE E (RE)ARRANJOS CURRICULARES}

"O dia 12 de novembro de 2010 entra para a história da educação de Brusque como o dia em que a Escola Ensino Fundamental Padre Theodoro Becker começou a sua metamorfose: da escola da celulose para a escola digital". Dessa forma, Pedroso (2012), integrante da equipe de professores-formadores do Programa Um Computador por Aluno (Núcleo Santa Catarina), descreveu a "caminhada" rumo ‘a "escola digital" desta instituição educacional de Brusque, município distante cerca de $100 \mathrm{~km}$ de Florianópolis/ SC.

Implantado em onze escolas de diferentes regiões, o início do PROUCA em Santa Catarina ocorreu em 2010. A época, junto a Universidade Federal de Santa Catarina (UFSC), foi constituída uma "Equipe de Formação e Pesquisa do Projeto UCA de Santa Catarina (Equipe UCA-UFSC)" a partir de uma ação orquestrada com a Universidade Federal do Rio Grande do Sul.

Em se tratando do envolvimento das escolas catarinenses que participavam dessa etapa piloto do PROUCA, ao que tudo indica, o marco simbólico das ações parece ter sido a realização de um encontro de "capacitação [...] dos membros da Equipe de Formação e do Grupo de professores-multiplicadores", promovido entre os dias 23 e 25 de agosto de 2010, em Florianópolis, tendo como foco a "liderança para uma gestão articulada de todo o processo" (Equipe UCA-UFSC, NTE/M e escolas). Dessa atividade participaram 
aproximadamente cinqüenta profissionais da educação que representavam cada um dos municípios onde seria implantado o PROUCA, quais sejam: Agrolândia, Brusque, Caçador, Chapecó, Florianópolis, Herval D’ Oeste, Jaraguá do Sul, Joinville, São Bonifácio e Tubarão. (Cerny; Ramos, 2012a).

Logo após, no final de setembro e ao longo dos meses de outubro e novembro de 2010, os laptops passaram, de fato, a ser distribuídos para as escolas de Santa Catarina que aderiram ao PROUCA. Em meio a atribulações de toda ordem, no final desse ano o saldo era o seguinte: de um total de onze, três escolas ainda nem tinham começado a usar os laptops e apenas cinco delas possuíam a "rede UCA funcionando" (Cerny; Ramos, 2012a).

Ocorre que, em Jaraguá do Sul, cidade do nordeste de Santa Catarina, a Escola Municipal de Ensino Fundamental Waldemar Schmitz recebeu os laptops do PROUCA somente em fevereiro de 2011. Os gestores do Colégio de Aplicação da Universidade Federal de Santa Catarina consideraram inadequado implantar tal programa enquanto a rede wireless não estivesse disponível aos alunos e professores. E, no Centro de Educação Adolfo Hedel, no município de Agrolândia (afastado $270 \mathrm{~km}$ de Florianópolis), entendeuse que o envio dos computadores ao final do ano letivo inviabilizava o uso pedagógico da máquina. Nessa mesma direção, ainda pesaram algumas dificuldades técnicas, como "os problemas no acesso à internet".

Da explanação que fizemos sobre a historicidade do PROUCA em Santa Catarina se torna possível perceber que o translado "da escola da celulose para a escola digital", como quer o professor-formador Pedroso (2012), de um ponto de vista operacional, não foi tranqüila. Na garimpagem de outros documentos que dão conta da implantação desse programa na Escola Ensino Fundamental Padre Theodoro Becker, pode-se ver que a "metamorfose" por ele propalada parece ter caráter eminentemente retórico.

De acordo com a leitura de Pedroso (2012), a processo de consolidação de uma "escola digital", em Brusque, teria sido iniciado no momento em que "cada aluno recebeu o seu classmate", ou seja, passou a ser portador de "um computador de mão (laptop) com diversas funcionalidades: conecta à Internet sem fio (wireless), grava som e vídeo, edita texto, planilha de cálculo e apresentações de slides, tem jogos educacionais e muito mais". Além disso, a máquina teria, ainda, a capacidade de assegurar a "conectividade e mobilidade" tanto aos alunos quanto aos seus professores.

Enfrentando as palavras deste professor-formador com o Relatório de Implantação do PROUCA na Escola de Ensino Fundamental Padre Theodoro Becker(Cerny; Ramos, 2012b), identificamos alguns descompassos. O mais aparente deles, diz respeito a dificuldade de recarregar as baterias de cada laptop cedido aos alunos dessa escola.

Além da utilização reduzida dos laptops distribuídos pelo PROUCA, dessa conjuntura decorria a indisponibilidade do uso pleno do Espaço Pedagógico Informatizado da escola em sua plenitude, assim como que o avanço do mundo "digital" celebrado por Pedroso (2012) obrigava-se a dialogar com uma infra-estrutura projetada para salvaguardar, dentre outros, papéis. 
Se pensada de um ponto de vista pedagógico (e curricular), a recontextualização do PROUCA naquela escola torna-se profícua à nossa reflexão. Ainda que as limitações desse artigo impossibilitem maiores digressões sobre nossas entradas metodológicas na Escola de Ensino Fundamental Padre Theodoro Becker, acreditamos ser importante mencionar que as fontes coletadas em campo são aqui entendidas como evidências das linguagens (práticas e representações educacionais) articuladas pelos mais diferentes interesses, usos e constrições curriculares do PROUCA.

É o que se pode deprender da citação abaixo quanto aos usos dos laptops nos dois últimos meses de 2010. Segundo a então diretora da Escola de Ensino Fundamental Padre Theodoro Becker, Sra. Vani:

A Escola não é mais a mesma. Vimos os alunos estudando, mostrando as atividades uns para os outros. O que um conseguiu fazer ensina para o outro. É visível as mudanças no interesse pela aprendizagem, além do envolvimento dos familiares que também querem aprender como lidar com essa ferramenta pedagógica tecnológica (Cerny; Ramos, 2012b).

Ao relacionarmos a fala dessa gestora ao relatório da equipe de professores-formadores (Núcleo Santa Catarina) sobre a implantação do PROUCA na escola aludida, as transformações enunciadas pela diretora parecem derivar do processo de reorganização das linguagens exercitadas nas disciplinas da matriz curricular do ensino fundamental brasileiro. Ilustrativo disso são as apropriações do programa pelos professores de Língua Portuguesa e de Língua Inglesa:

O [...] Um Computador por Aluno, foi colocado em prática pelos professores de Língua Portuguesa e Língua Inglesa que desenvolveram o Projeto ECA (Estatuto da Criança e Adolescente) na sala de aula com a 5a série do Ensino Fundamental. "É fantástico as possibilidades de desenvolvimento de leitura, escrita e outras linguagens que esta ferramenta pedagógica fornece. Com ela podemos realizar leitura e pesquisa ao mesmo tempo, desenvolvendo nos alunos o desejo de saber, do querer aprender sempre mais novos conhecimentos. O laptop propicia aos alunos perceberem, na prática, a relação que existe entre as diversas linguagens, como sons, imagens e escrita", afirma o professor [de Língua Portuguesa]. Com o uso do laptop os alunos passaram a se interessar mais pela linguagem dos textos, pelo prazer da aprendizagem. [...] A professora de Inglês [...] conta que com o uso do computador dinamizou muito mais as aulas. "Podemos realizar várias atividades e compartilhá-las através de e-mail e do hipertexto" (Cerny; Ramos, 2012b).

De outro modo, o professor de História da mesma escola narrou os usos que fez dos laptops em suas aulas. Mesmo diante depercalços, como a chegada tardia dos computadores à escola, o docente já demonstrava seu otimismo em relação à inclusão dessas máquinas em suas aulas. Disse ele:

[...] É impressionante como essa máquina [computador] consegue captar a atenção de todos, indistintamente. Diante disso, com o pouco tempo possível até aqui, fica uma grande expectativa no sentido de uma utilização mais efetiva a partir do próximo ano letivo e, certamente, haverá uma maior aprendizagem com mais esse instrumento de mediação de conhecimento. 0 
que já foi possível fazer [em 2010], neste ano, foi utilizar os computadores para complementar alguns estudos, através do uso da internet e que possibilitou a observação dos conteúdos sob mais de um ponto de vista. $\mathrm{Na}$ 6a série "uma outra visão da independência do Brasil"; na 7a série "Conceitos de Capitalismo e Comunismo", no estudo das Revoluções Russas; e na 8a série, informações mais abrangentes sobre "a nova República e o plano Real" (Cerny; Ramos, 2012b).

Em que pesem os esforços destes professores para dinamizar suas práticas pedagógicas e as prescrições advindas da matriz curricular da escola onde atuam, não se pode deixar de notar certas permanências; certos acúmulos de passado transbordando do exercício de seus ofícios no presente.

Imiscuídos em seus fazeres, expectativas de futuro carregadas de um tom celebratório em relação às tecnologias da informação e comunicação deixam ver sentimentos de insatisfação com as linguagens historicamente acumuladas no cotidiano da escola onde atuam, tais como a impossibilidade de conciliar "leitura e pesquisa ao mesmo tempo", a falta de dinamicidade das aulas, a dificuldade em romper com o caráter monolítico e dogmático de algumas explicações sobre o passado, estudando determinados "conteúdos sob mais de um ponto de vista".

Ainda nessa mesma direção, não é prolixo dizermos que mais um desejo de ruptura com o presente transpassa as projeções de futuro de alunos e professores da Escola de Ensino Fundamental Padre Theodoro Becker: a dimensão abstrata dos conteúdos escolares e das linguagens mobilizadas em sala para garantir o ensino e a aprendizagem. Observemos o depoimento de dois alunos dessa instituição: "As aulas ficaram muito mais interessantes. Agora aprendemos com mais vontade" conta o aluno Alisson Cruz. Para a aluna Ana Flávia Duarte "o laptop facilita na aprendizagem dos conteúdos, pois antes os professores faziam o maior esforço para que visualizássemos a matéria para que pudéssemos compreender melhor. Agora é bem mais prático e nossa aprendizagem é melhor" (Cerny; Ramos, 2012b).

É pelo cruzamento entre o contentamento dos alunos com aulas do presente (produzido pela ruptura com práticas escolares passadas) às expectativas de futuro dos docentes aludidos, que podemos enxergar os sentidos de certas linguagens que foram mobilizadas para assegurar o sucesso pedagógico da implantação do PROUCA na escola investigada.

Ao que nos parece, tal programa foi transformado em um artefato capaz de dividir e interpolar linguagens e, com isto, nutrir ambições educacionais carregadas de desejos de mudanças. Um esboço de "sacramento da linguagem", conforme nos lembra Agamben (2011): movimento pelo qual se funde a dimensão metafísica e mágicoreligiosa do discurso religioso (pelo rito, a superação do imediato) ao caráter retórico de certas enunciações políticas (retórica do devir). Nada mais apropriado para se pensar o cotidiano escolar brasileiro num tempo no qual as tecnologias da informação e comunicação rumam à ubiqüidade. 


\section{PALAVRAS FINAIS: O PROUCA E A SEDUÇÃO PELO DIGITAL}

Em que medida o Programa Um Computador por Aluno pode ser considerado referente da sedução contemporânea por tudo digitalizar? Mais do que responder assertivamente a essa questão, o que pretendemos colocar em suspeição são tentativas governamentais que, desde a segunda metade dos anos 1990, vem conferindo às tecnologias da informação e comunicação a capacidade de atualizar uma escola secularizada e habilitála ao diálogo com os fluxos de globalização que circulam pelo planeta.

Ao examinarmos as fontes que coletamos é possível afirmar que o PROUCA parece ser o contemporâneo que moderniza as tecnologias que, no passado, foram enviadas de modo massificado para as escolas públicas brasileiras. De maneira interessante, parece que tal programa está envolvido num jogo de linguagem intrigante: o "analogismo" dos aparelhos de televisão e vídeo-cassete, assim como a estabilidade dos conteúdos educativos que integram os Kits Tecnológicos do TV Escola, é solapado em favor da dispersão do digital na escola. Assim, cada computador que adentra o universo escolar, na perspectiva dos órgãos oficiais de gestão da educação brasileira (e catarinense), é capaz de impulsionar um sistema de crença segundo o qual o digital é sempre mais atual, mais moderno e sempre melhor qualidade.

Sem sombra de dúvida, estamos diante de um momento singular na história da educação pública brasileira; momento este no qual as instituições de educação básica se vêm interpeladas por dois processos que reivindicam lugar na cultura escolar: a assemblage de temporalidades e espacialidades que (des)orientam as múltiplas sociabilidades juvenis e a ubiqüidade digital que se suporta em tecnologias da informação e comunicação cada vez mais complexas. Em meio a isso, o que caberia às escolas? Ao que nos parece, uma resposta para essa pergunta somente poderia ser construída se considerarmos o seguinte como pressuposto: desconfiar do messianismo pedagógico que traveste as tecnologias da informação e comunicação quando enviadas sob qualquer forma às escolas. TV Escola, Kits Tecnológicos e/ou PROUCA... Eis parte da assemblage de tempos, espaços, ubiqüidades e imagens de sociabilidades juvenis que exige lugar na cultura escolar contemporânea. 


\title{
"A COMPUTER FOR EACH STUDENT IN PUBLIC SCHOOLS OF SANTA CATARINA" PROGRAM: NOTES ON CONTEMPORARY SEDUCTION FOR GLOBAL DIGITIZING
}

\begin{abstract}
This article examines some of the contracts of the Brazilian government aimed at dissemination of information technologies and communication in teaching in public school. From a wide range of sources collected in the field, we attempt to detect the meanings of the languages involved with deploying and redefining the curriculum of the program "One Computer for each Student" in a public school in the city of Brusque, in southern Brazil. In general, the article concludes that the spread of information technologies and communication in the public schools of the country seems to be a form of government bodies to propose languages supposedly aimed at dealing with contemporary anxieties concerned with global digitizing.
\end{abstract}

Keywords: Information technology and communication. Language. Curriculum.

\section{REFERÊNCIAS}

AGAMBEN, G. O sacramento da linguagem: arqueologia do juramento. Belo Horizonte: UFMG, 2011.

BRASIL. Ministério da Educação. Conheça o UCA. Disponível em: <www.uca.gov.br/ institucional/projeto.jsp>. Acesso: 03 abr. 2012a.

Ministério da Educação. Assessoria de Comunicação Social do MEC. Escola não pode ficar à margem da evolução da tecnologia, diz ministro. Disponível em: http:// portal.mec.gov.br/index.php?option=com_content\&view=article\&id=17498: escolanao-pode-ficar-a-margem-da-evolucao-da-tecnologia-diz-ministro\&catid=222. Acesso: 03 abr. 2012b.

BRASIL. Ministério da Educação. Secretaria de Educação a Distância. O que é a TV ESCOLA? Disponível em: http://portal.mec.gov.br/seed/index.php?option=content\&tas k=view\&id=69\&Itemid=. Acesso: 14 out. 2007. 
Secretaria de Educação a Distância. Programa Nacional de Informática na Educação. Relatório e Indicadores Estatísticos. Disponível em: <http://sip.proinfo.mec. gov.br/relatorios/indicadores_rel.html>. Acesso: 23 jan. 2008.

CERNY, R. Z; RAMOS, E. M. F. Relatório da Implantação do Projeto UCA em SC 2010/2011. Florianópolis: UFSC, 31 jan. 2012a.

Relatório da Implantação do Projeto UCA em SC 2010/2011: relatório EEF Padre Theodoro Becker - Brusque. Florianópolis, UFSC, 31 jan. 2012b.

PEDROSO. R. S. Escola Theodoro Becker começa sua caminhada para a Escola Digital. Disponível em: <http://uca-sc.blogspot.com.br/2010/11/escola-theodoro-beckercomeca-sua.html>. Acesso: 10 jun. 2012

\section{SOBRE OS AUTORES}

Graduado em História pela Universidade da Região de Joinville (UNIVILLE) e
mestre em Educação pela Universidade do Estado de Santa Catarina. É professor
nos Departamentos de História e Design e coordenador do curso de Sociologia
da UNIVILLE. Nos últimos anos tem coordenado pesquisas sobre a inclusão de
tecnologias da informação e comunicação no currículo escolar e também se
dedicado à produção de recursos didáticos audiovisuais direcionados para o
ensino de História.

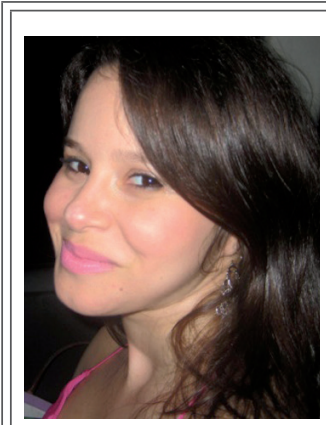

Gabriele

Bacharel em Violino pela Universidade do Estado de Santa Catarina (UDESC) e Mestre em Música subárea Educação Musical pela mesma universidade. Durante o mestrado desenvolveu pesquisa relacionada à formação de professores de música e tecnologia. Atualmente é Bolsista de Desenvolvimento Industrial - Nível B (CNPq) do Projeto de Pesquisa "Aulas Conectadas: mudanças curriculares e aprendizagem colaborativa entre as escolas do projeto UCA em Santa Catarina".

Mendes da Silva 


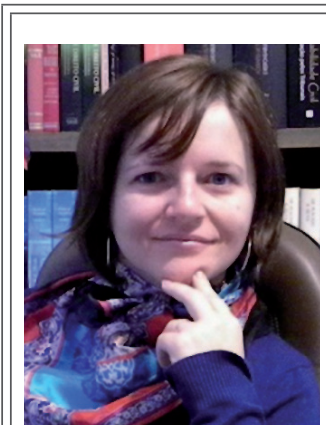

Geovana

Mendonça Lunardi Mendes
Graduada em Pedagogia pela Universidade Federal de Santa Catarina, mestrado em Educação pela Universidade Federal de Santa Catarina, doutorado em Educação: História, Política, Sociedade pela Pontifícia Universidade Católica de São Paulo com estágio de doutoramento em Currículo e Tecnologias na Universidade do Minho - Portugal. Realizou Pós-Doutorado na Argentina (Universidad de San Andres - Buenos Aires) e nos EUA (Ashland University - Ohio) na área de Currículo e Novas Tecnologias com bolsa Capes (2010 e 2011). É Professora Associada da Universidade do Estado de Santa Catarina (UDESC), atuando no Centro de Ciências da Educação, no curso de Pedagogia e no Mestrado e Doutorado do Programa de Pós-Graduação em Educação, na linha de pesquisa Educação, Comunicação e Tecnologia. 